\title{
Agrobacterium-Mediated Transformation of Fusarium oxysporum: An Efficient Tool for Insertional Mutagenesis and Gene Transfer
}

\author{
E. D. Mullins, X. Chen, P. Romaine, R. Raina, D. M. Geiser, and S. Kang
}

First, second, third, fifth, and sixth authors: Department of Plant Pathology, The Pennsylvania State University, University Park; and fourth author: Department of Biology, The Pennsylvania State University, University Park 16802.

Accepted for publication 17 October 2000.

\begin{abstract}
Mullins, E. D., Chen, X., Romaine, P., Raina, R., Geiser, D. M., and Kang, S. 2001. Agrobacterium-mediated transformation of Fusarium oxysporum: An efficient tool for insertional mutagenesis and gene transfer. Phytopathology 91:173-180.

Agrobacterium tumefaciens-mediated transformation (ATMT) has long been used to transfer genes to a wide variety of plants and has also served as an efficient tool for insertional mutagenesis. In this paper, we report the construction of four novel binary vectors for fungal transformation and the optimization of an ATMT protocol for insertional mutagenesis, which permits an efficient genetic manipulation of Fusarium oxysporum and other phytopathogenic fungi to be achieved. Employing the binary vectors, carrying the bacterial hygromycin B phosphotransferase gene $(h p h)$ under the control of the Aspergillus nidulans trpC promoter as a selectable marker, led to the production of 300 to 500 hygromycin B resistant transformants per $1 \times 10^{6}$ conidia of $F$. oxysporum, which is at least an order of magnitude higher than that previously accomplished. Transformation efficiency correlated strongly with the duration of cocultivation of fungal spores with Agrobacterium tumefaciens cells and significantly with the number of Agrobacteruium tumefaciens cells present during the cocultivation period $(r=0.996 ; n=3 ; P<0.01)$.

hygromycin B resistance. Growing Agrobacterium tumefaciens cells in the presence of acetosyringone (AS) prior to cocultivation shortened the time required for the formation of transformants but decreased to $53 \%$ the percentage of transformants containing a single T-DNA insert per genome. This increased to over $80 \%$ when Agrobacterium tumefaciens cells grown in the absence of AS were used. There was no correlation between the average copy number of T-DNA per genome and the colony diameter of the transformants, the period of cocultivation or the quantity of Agrobacterium tumefaciens cells present during cocultivation. To isolate the host sequences flanking the inserted T-DNA, we employed a modified thermal asymmetric interlaced PCR (TAIL-PCR) technique. Utilizing just one arbitrary primer resulted in the successful amplification of desired products in $90 \%$ of those transformants analyzed. The insertion event appeared to be a random process with truncation of the inserted TDNA, ranging from 1 to $14 \mathrm{bp}$ in size, occurring on both the right and left border sequences. Considering the size and design of the vectors described here, coupled with the efficiency and flexibility of this ATMT protocol, it is suggested that ATMT should be regarded as a highly efficient alternative to other DNA transfer procedures in characterizing those genes important for the pathogenicity of $F$. oxysporum and potentially those of other fungal pathogens.
\end{abstract} All transformants tested remained mitotically stable, maintaining their
In the filamentous fungi transformation with DNA that does not exhibit homology with the fungal genome results in heterologous integration of transforming DNA into the genome, which makes it possible to use the transforming DNA as an insertional mutagen to disrupt genes and ultimately assist in the study of plant disease. A big advantage of this technique over chemical or radiation mutagenesis is that the mutated gene is tagged by the transforming DNA, which can be used to clone the corresponding wild-type gene by plasmid rescue or polymerase chain reaction (PCR). An insertional mutagenesis technique, termed restriction enzymemediated integration (REMI), has been successfully used to transform diverse filamentous fungi (1-3,11,16,23,26,30-32,34,37). This technique has allowed for the efficient isolation of genes important for pathogenicity from several fungal pathogens (1-3, $16,23,30,34,37)$.

Although an efficient tool for tagging and cloning pathogenicity genes from fungal pathogens, a significant limitation of REMI is that a substantial portion (20 to $100 \%$ ) of generated mutants appear to be untagged by the transforming DNA $(2,11,23,31,34)$. It has been proposed that cutting of the chromosome by a restriction enzyme followed by imperfect DNA repair during transformation is responsible for those untagged mutations (34). In Gibberella

Corresponding author: S. Kang; E-mail address: sxk55@psu.edu

Publication no. P-2000-1120-01R

(c) 2001 The American Phytopathological Society fujikuroi, the transformation process itself caused deletions and chromosome translocations unlinked to the inserted plasmid in both the presence and absence of restriction enzymes (23). Genetic crosses have been used to identify untagged mutants in which the mutant phenotype fails to cosegregate with the selectable marker on the inserted plasmid. However, for fungi lacking a sexual stage, the cloning of tagged genes and subsequent functional complementation by transformation are necessary to verify if a given mutant has been tagged. Especially, when REMI generates a high percentage of mutants with multiple copies of inserted plasmid, such a verification process can be quite time consuming.

Agrobacterium tumefaciens-mediated transformation (ATMT) has long been used to transfer genes to a wide variety of plants and has also been used extensively as a tool for insertional mutagenesis in Arabidopsis thaliana $(9,12,20)$. More recently, several fungi have been transformed with Agrobacterium tumefaciens $(4,8,15)$. For insertional mutagenesis, this technique offers huge potential as an alternative tool to REMI (10). One of the principal advantages of ATMT over conventional transformation techniques is the versatility it provides in choosing which starting material to transform. Applicable to several fungi, Agrobacterium tumefaciens can transform protoplasts, hyphae, spores (8), and blocks of mushroom mycelial tissue (P. Romaine, unpublished data).

Binary vector pUR5750 for transforming fungi to hygromycin $\mathrm{B}$ resistance, which was reported by de Groot et al. (8), is approximately $14 \mathrm{~kb}$ long. Although its large size is unlikely to become a hindrance during the generation of hygromycin B-resistant 
transformants, the cloning of additional genes on the vector for gene transfer to fungi is likely to be difficult. In addition, pUR5750 contains only four unique restriction sites for gene cloning, which also limits its utility as a vehicle for delivering genes into fungi. One of the main objectives of this work was to construct new binary vectors that are more versatile than pUR5750 for gene transfer in various fungi.

Although Fusarium vascular wilt disease, caused by Fusarium oxysporum, is both widespread in nature and very destructive, our knowledge on its mechanisms of pathogenesis is very limited. Application of ATMT as a tool for insertional mutagenesis is likely to provide such knowledge. Given the asexual nature of $F$. oxysporum, it is important to optimize conditions of ATMT for maximizing the number of transformants carrying a single copy of T-DNA. Additional objectives of this work were to (i) find such conditions and (ii) develop an efficient procedure that would allow for the rescue of inserted T-DNA along with the adjacent host sequences.

\section{MATERIALS AND METHODS}

Fungal material. F. oxysporum strain O-685 was obtained from the Fusarium Research Center collection (The Pennsylvania State University, University Park) and was stored as a monoconidial culture at $-80^{\circ} \mathrm{C}$. Material was revitalized on $1 \%$ water agar supplemented with irradiated carnation leaf pieces (CLA) (13). The incubation period required to induce conidial formation was typi- cally 12 days at $22^{\circ} \mathrm{C}$ under continuous fluorescent light. Conidia were collected by adding sterile water to the plates and rubbing the surface of the CLA with the end of a sterile micropipette tip. Conidial suspension was filtered through Miracloth (CalbiochemBehring, La Jolla, CA) to remove large particles.

Plasmid construction. All the vectors described in this study (Fig. 1) were constructed on the backbone of pCAMBIA1300 (CAMBIA, Canberra, Australia). A 1.4-kb fragment of pCSN44 (33), containing the hygromycin B resistance $(h p h)$ gene under the Aspergillus nidulans trpC promoter, was isolated by digesting pCSN44 with BamHI and HindIII, and subsequently the ends of the fragment were blunted with DNA polymerase I large fragment in the presence of dNTPs. The hph gene under the Cauliflower mosaic virus $35 \mathrm{~S}$ (CaMV35S) promoter was removed from pCAMBIA1300 by digesting the plasmid with XhoI and BstXI, and its restricted ends were blunted as described above. This fragment was ligated to the 1.4-kb fragment of pCSN44 to produce pBHt1 $(8.4 \mathrm{~kb})$. Plasmid pDHt $(7.1 \mathrm{~kb})$ was constructed by self-ligating the digested pCAMBIA1300 without an insert. To construct pBHt2 $(8.4 \mathrm{~kb})$, the 1.4-kb HpaI fragment of pCB1004 (6) carrying the modified $h p h$ gene under the Aspergillus nidulans $\operatorname{trpC}$ promoter, was ligated to the same fragment of pCAMBIA1300 that was used to construct pBHt1. In both pBHt1 and pBHt2 the $3^{\prime}$ end of the $h p h$ gene was ligated to the CaMV35S poly (A) signal. Plasmid pKHt $(10.6 \mathrm{~kb})$ contains a $2.2-\mathrm{kb}$ fragment containing the ColE1 replication of origin and the gene con-

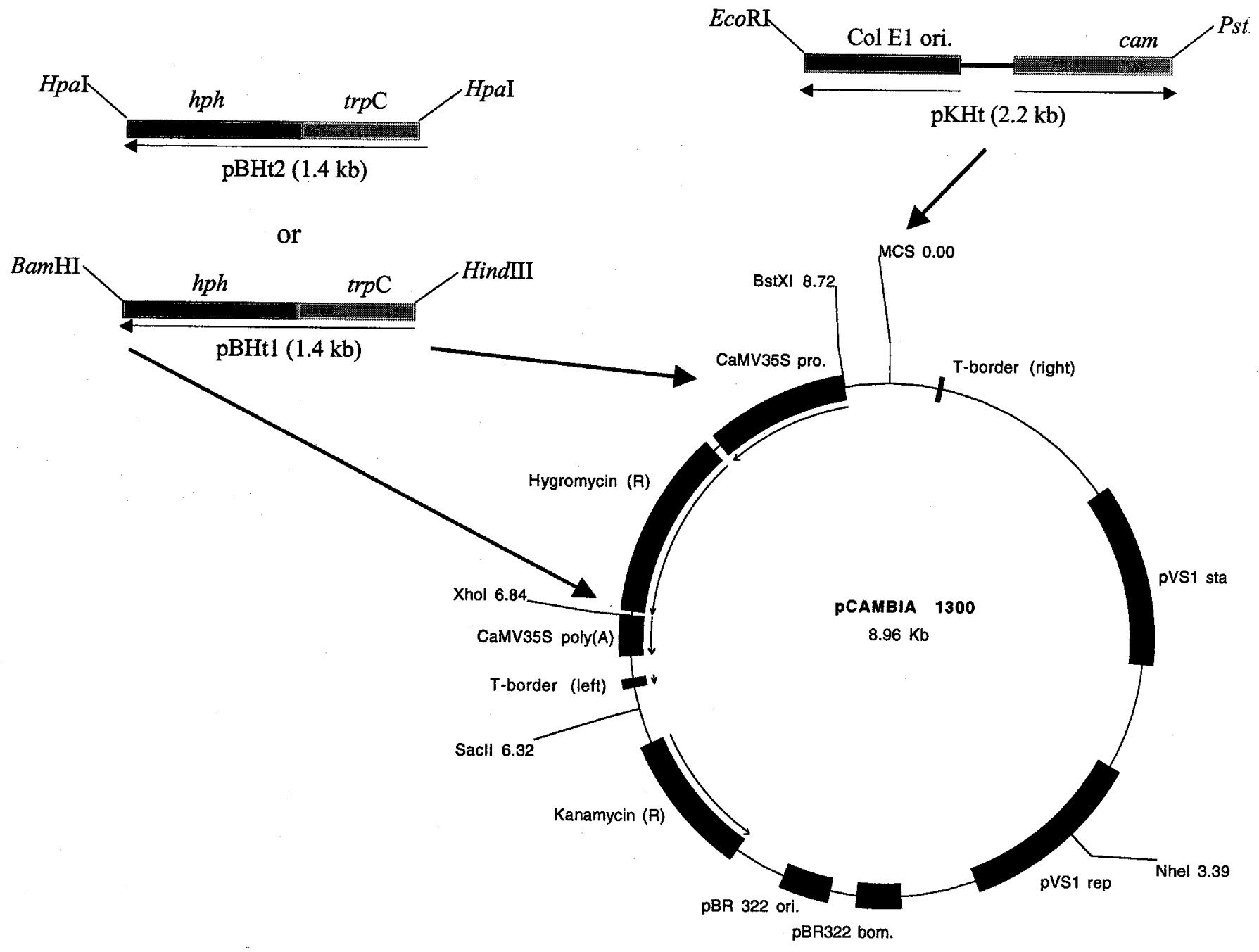

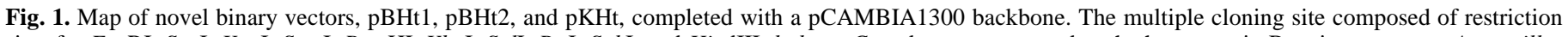

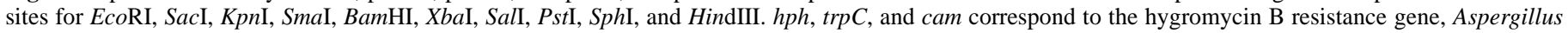
nidulans trp $C$ promoter and chloramphenicol resistance gene, respectively. Arrows denote direction of their transcription. 
ferring chloramphenicol resistance between the EcoRI and PstI sites of pBHt2. This 2.2-kb fragment was amplified by PCR from pBCSK (Stratagene, La Jolla, CA) by the following two primers: ECO-1 (5'-GGGCGAATTCTCTTCCGCTTCCTCGCT-3') and PST-1 (5'-AAGGAACTGCAGTATGAGTATTCAACATT-3'). The underlined sequences in these primers indicate the EcoRI and PstI sites, respectively, that were introduced to facilitate the subsequent cloning of this fragment in $\mathrm{pBHt} 2$. The amplified DNA was separated on a $0.7 \%$ agarose gel. A DNA fragment of approximately $2.2 \mathrm{~kb}$ was cut from the gel, purified with a gel ex-

TABLE 1. Conditions used for thermal asymmetric interlaced polymerase chain reaction (TAIL-PCR) protocol ${ }^{\mathrm{a}}$

\begin{tabular}{|c|c|c|}
\hline Primary PCR reaction & Secondary PCR reaction & Tertiary PCR reaction \\
\hline $92^{\circ} \mathrm{C}: 2 \mathrm{~min}$ & $94^{\circ} \mathrm{C}: 10 \mathrm{~s} * * *$ & $94^{\circ} \mathrm{C}: 10 \mathrm{~s}$ \\
\hline $95^{\circ} \mathrm{C}: 1 \mathrm{~min}$ & $66^{\circ} \mathrm{C}: 1 \mathrm{~min}^{* * *}$ & $94^{\circ} \mathrm{C}: 15 \mathrm{~s} * * * *$ \\
\hline $94^{\circ} \mathrm{C}: 30 \mathrm{~s}^{*}$ & $72^{\circ} \mathrm{C}: 2 \min ^{* * *}$ & $42^{\circ} \mathrm{C}: 15 \mathrm{~s} * * * *$ \\
\hline $66^{\circ} \mathrm{C}: 1 \mathrm{~min}^{*}$ & $94^{\circ} \mathrm{C}: 10 \mathrm{~s} * * *$ & $72^{\circ} \mathrm{C}: 2 \min ^{* * * *}$ \\
\hline $72^{\circ} \mathrm{C}: 2 \mathrm{~min} *$ & $66^{\circ} \mathrm{C}: 1 \mathrm{~min}^{* * * *}$ & $72^{\circ} \mathrm{C}: 5 \mathrm{~min}$ \\
\hline $94^{\circ} \mathrm{C}: 30 \mathrm{~s}$ & $72^{\circ} \mathrm{C}: 2 \min ^{* * *} *$ & - \\
\hline $30^{\circ} \mathrm{C}: 3 \mathrm{~min}$ & $94^{\circ} \mathrm{C}: 10 \mathrm{~s} * * *$ & - \\
\hline Ramp to $72^{\circ} \mathrm{C}$ over $3 \mathrm{~min}$ & $44^{\circ} \mathrm{C}: 1 \mathrm{~min}^{* * *}$ & - \\
\hline $72^{\circ} \mathrm{C}: 2 \mathrm{~min}$ & $72^{\circ} \mathrm{C}: 2 \min ^{* * *}$ & - \\
\hline $94^{\circ} \mathrm{C}: 5 \mathrm{~s}^{* *}$ & $72^{\circ} \mathrm{C}: 5 \mathrm{~min}$ & - \\
\hline $44^{\circ} \mathrm{C}: 1 \min ^{* *}$ & - & - \\
\hline $72^{\circ} \mathrm{C}: 2 \min ^{* *}$ & - & - \\
\hline $94^{\circ} \mathrm{C}: 5 \mathrm{~s} * * *$ & - & - \\
\hline $66^{\circ} \mathrm{C}: 1 \min ^{* * *} *$ & - & - \\
\hline $72^{\circ} \mathrm{C}: 2 \min ^{* * *}$ & - & - \\
\hline $94^{\circ} \mathrm{C}: 5 \mathrm{~s}^{* * *}$ & - & - \\
\hline $66^{\circ} \mathrm{C}: 1 \mathrm{~min}^{* * *}$ & - & - \\
\hline $72^{\circ} \mathrm{C}: 2 \min ^{* * *}$ & - & - \\
\hline $94^{\circ} \mathrm{C}: 5 \mathrm{~s} * * *$ & - & - \\
\hline $44^{\circ} \mathrm{C}: 1 \mathrm{~min}^{* * *}$ & - & - \\
\hline $72^{\circ} \mathrm{C}: 2 \min * * *$ & - & - \\
\hline $72^{\circ} \mathrm{C}: 5 \mathrm{~min}$ & - & - \\
\hline
\end{tabular}

traction kit (QIAquick; Qiagen, Valencia, CA), and digested with EcoRI and PstI. The resulting fragment was cloned between the EcoRI and PstI sites of pBHt2 to produce pKHt.

Transformation. Agrobacterium tumefaciens strain AGL-1 (provided by M. Guiltinan at Penn. State), containing an appropriate binary vector, was grown at $28^{\circ} \mathrm{C}$ for 2 days in minimal medium (MM) (17) supplemented with kanamycin $(50 \mu \mathrm{g} / \mathrm{ml})$. The Agrobacterium tumefaciens cells were diluted to (optical density) $\mathrm{OD}_{600}=0.15$ in induction medium (IM) (4), both in the presence (IM+AS) and absence (IM-AS) of $200 \mu \mathrm{M}$ acetosyringone (AS). The cells were grown for an additional $6 \mathrm{~h}$ before mixing them with an equal volume of a conidial suspension from strain O-685 $\left(1 \times 10^{6}\right.$ conidia per $\left.\mathrm{ml}\right)$. This mix $(200 \mu \mathrm{l}$ per plate $)$ was plated on a $0.45-\mu \mathrm{m}$ pore, $45-\mathrm{mm}$ diameter nitrocellulose filter (Whatman, Hillsboro, OR) and placed on cocultivation medium (same as IM except that it contains $5 \mathrm{mM}$ glucose instead of $10 \mathrm{mM}$ glucose) in the presence and absence of $200 \mu \mathrm{M}$ AS. Following incubation at $25^{\circ} \mathrm{C}$ for 2 days, the filter was transferred to $\mathrm{MM}$ containing hygromycin $\mathrm{B}(75 \mu \mathrm{g} / \mathrm{ml})$ as a selection agent for transformants and cefotaxime $(200 \mu \mathrm{M})$ and moxalactum $(100 \mu \mathrm{g} / \mathrm{ml})$ to kill the Agrobacterium tumefaciens cells. Individual transformants were transferred into 24-well plates (Costar Scientific Corp., Cambridge, MA) containing $1.5 \mathrm{ml}$ of CLA amended with hygromycin B $(75 \mu \mathrm{g} / \mathrm{ml})$ and incubated until conidiogenesis. Conidia of individual transformants were suspended with sterile water and plated on potato dextrose agar (PDA; Difco Laboratories, Detroit) supplemented with hygromycin B $(75 \mu \mathrm{g} / \mathrm{ml})$. To create monoconidial cultures, one germinating conidium from each transformant was picked and transferred to CLA containing hygromycin B $(75 \mu \mathrm{g} / \mathrm{ml})$ in either a small petri plate $(60 \times 15 \mathrm{~mm})$ or a $15-\mathrm{ml}$ plastic tube. Spores from these monoconidial cultures were stored in $20 \%$ glycerol at $-80^{\circ} \mathrm{C}$ until further analysis.

DNA extraction and analysis. Transformants were grown for 5 days at room temperature in $50 \mathrm{ml}$ of liquid potato dextrose broth (Difco Laboratories) amended with hygromycin B (75 $\mu \mathrm{g} / \mathrm{ml})$.

A $\quad \mathrm{RB}-1, \mathrm{~T}_{\mathrm{m}}=64^{\circ} \mathrm{C} \quad \mathrm{RB}-2, \mathrm{~T}_{\mathrm{m}}=62^{\circ} \mathrm{C} \longrightarrow$

aagcttggcactggccgtcgttttacaacgtcgtgactgggaaaaccctggcgttacccaacttaatcgccttgcagcacatcccc

$\mathrm{RB}-3, \mathrm{~T}_{\mathrm{m}}=61^{\circ} \mathrm{C}$

ctttcgccagctggcgtaatagcgaagaggcccgcaccgatcgcccttcccaacagttgcgcagcctgaatggcgaatgctagagc

agcttgagcttggatcagattgtcgtttcccgccttcagt taaactatcag tg t tGACAGGATATAMTGGCGGGMAAAC

B $\underset{\text { gataagggaattagggttcctatagggtttcgctcatgtgttgagcatataagaaaccctagtatgtatttgtatttgtaaaata }}{\stackrel{\mathrm{LB}-1, \mathrm{~T}_{\mathrm{m}}=64^{\circ} \mathrm{C} \longrightarrow \mathrm{LB}-2, \mathrm{~T}_{\mathrm{m}}=60^{\circ} \mathrm{C}}{\longrightarrow}}$ cttctatcaataaaatttctaattcctaaaaccaaaatccagtactaaaatccagatcccccgaattaattcggcgttaattcagt acattaaaaacgtccgcaatgtgttattaagttgtctaagcgtcaatt tGTMPACACCACAATATATCCTGCC

\section{C}

$$
\mathrm{AD}-1, \mathrm{~T}_{\mathrm{m}}=47^{\circ} \mathrm{C}: \text { WAGTGNAGWANCANAGA }
$$

Fig. 2. A, Right border (RB) and $\mathbf{B}$, left border (LB) ends of the T-DNA sequence showing the position and melting temperatures ( $T_{m}$ 's) of the primers employed for thermal asymmetric interlaced polymerase chain reaction. Bold uppercase letters indicate the 24-bp imperfect repeat that was cleaved at the indicated positions prior to insertion. $\mathbf{C}$, The sequence and $T_{m}$ of the arbitrary degenerate primer (AD-1); $\mathrm{W}=\mathrm{A}$ and $\mathrm{T}$; and $\mathrm{N}=\mathrm{A}, \mathrm{C}, \mathrm{G}$, and $\mathrm{T}$. 
Mycelial mats were collected by vacuum-infiltration on Whatman No. 1 filter paper and washed several times with sterile water before drying between paper towels. Mats were ground to a fine powder in liquid nitrogen, and DNA was extracted as previously described (29). A miniprep procedure developed for Magnaporthe grisea (35) was also employed for isolating DNA from some transformants.

To determine the copy number of T-DNA (number of T-DNA insertions throughout the host genome), extracted DNA was digested with EcoRI and the products separated by electrophoresis on a $0.7 \%$ agarose gel in $1 \times$ TAE ( $40 \mathrm{mM}$ Tris-acetate, $\mathrm{pH} 8.5$ and $2 \mathrm{mM}$ EDTA) buffer containing ethidium bromide. The gel was treated with $0.25 \mathrm{M} \mathrm{HCl}$ before blotting onto a nylon membrane (Hybond-XL; Amersham Pharmacia, Buckinghamshire, U.K.) with $0.4 \mathrm{M} \mathrm{NaOH}$ as transfer buffer. Prehybridization, hybridization, and high stringency washes of the membrane were completed at $65^{\circ} \mathrm{C}$ as described by the manufacturer. The 1.4-kb HpaI fragment of pCB1004 described above was labeled with ${ }^{32} \mathrm{P}$-labeled dCTP and used as a probe to determine the T-DNA copy number.

Cloning and sequencing of genomic DNA flanking T-DNA. Employing novel primers, a thermal asymmetric interlaced PCR (TAIL-PCR) protocol (Table 1; 24,25) was used for cloning genomic DNA flanking inserted T-DNA from 10 randomly selected transformants. The right border primers (RB-1, -2, and -3) and the left border primers (LB-1, -2 , and -3) and the arbitrary degenerate (AD-1) primer used (Fig. 2) were designed such that their melting temperatures $\left(T_{m}\right.$ 's) would ensure maximum thermal asymmetric priming. $T_{m}$ 's were calculated as previously described (27). A thermal cycler (PTC-100; MJ Research Inc., Watertown, MA) was used for the TAIL-PCR. The tertiary TAIL-PCR product of each transformant showing the highest intensity was purified using QIAquick columns (Qiagen) and sequenced on an automated DNA sequencer (ABI Prism 377) by a terminator cycle sequencing kit (ABI Prism BigDye; Applied Biosystems, Foster City, CA). The innermost specific primer, either RB-3 or LB-3, was used as the sequencing primer.

Mitotic stability of transformants. To determine the stability of transformants, five randomly selected transformants were cultured on PDA without hygromycin B. Following colonization of

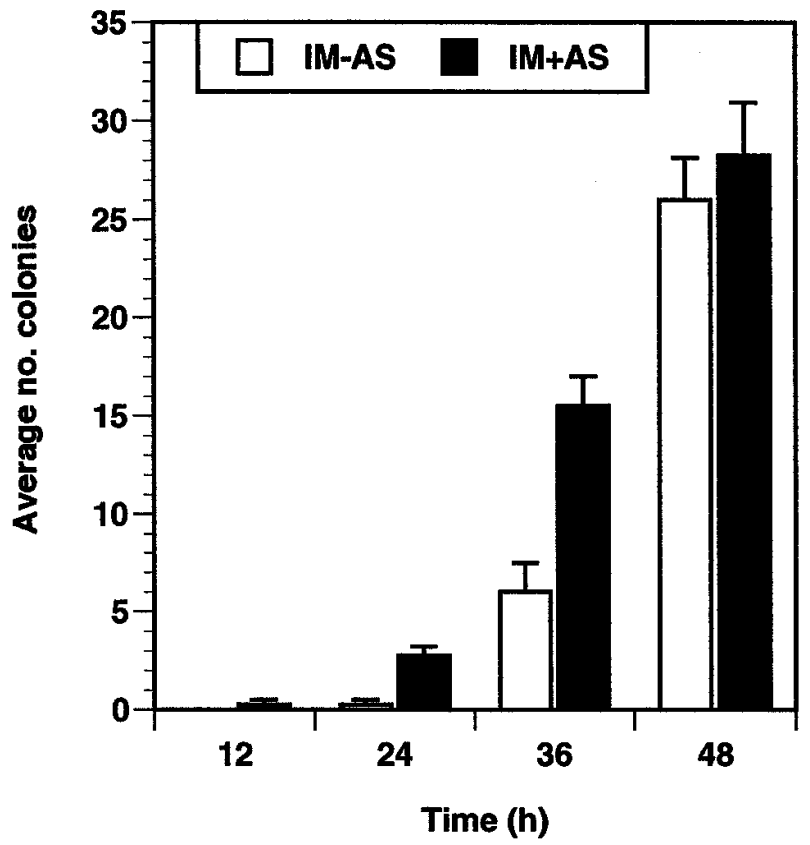

Fig. 3. Effect on transformation efficiency of increasing the cocultivation time with which Agrobacterium tumefaciens cells and 0-685 conidia were incubated. Agrobacterium tumefaciens cells were incubated in induction medium (IM) in the presence or absence of acetosyringone (AS). Data presented as the average of four plates per treatment. Error bars indicate standard error. each plate, a mycelial plug was taken from the edge of the culture and transferred onto fresh PDA. This procedure was repeated an additional five times after which 13 germinating monoconida from each transformant line were isolated and cultured. Resistance of these monoconidial cultures to hygromycin B was tested by growing them on PDA containing hygromycin B $(75 \mu \mathrm{g} / \mathrm{ml})$.

\section{RESULTS}

Agrobacterium tumefaciens mediated transformation of $\boldsymbol{F}$. oxysporum. We replaced the $h p h$ gene under the CaMV35S promoter in pCAMBIA1300 with the hph gene under the Asperigillus nidulans trpC promoter to produce $\mathrm{pBHt}$. Cocultivation of Agrobacterium tumefaciens cells carrying pBHt1 with conidia of $F$. oxysporum strain O-685 in the presence of AS led to the appearance of hygromycin B-resistant colonies approximately 4 to 5 days after transfer to the selection medium. In the absence of AS during cocultivation, no transformants were formed. Interestingly, both pBHt1 and pCAMBIA1300 successfully transformed this strain, suggesting that the CaMV35S promoter can function in $F$. oxysporum. Although the average colony size of transformants by pCAMBIA1300 was consistently smaller than that by pBHt1, no significant difference existed in the number of transformants between these constructs. Subsequently, all the transformation experiments described below were performed with pBHt1 unless indicated otherwise. Transformation efficiency was in the range of 300 to 500 transformants per $1 \times 10^{6}$ conidia when Agrobacterium tumefaciens cells were grown in the presence of AS prior to $48 \mathrm{~h}$ of cocultivation. An assessment of the mitotic stability of five transformants showed that all of them maintained their hygromycin B resistance after being cultured for six generations in the absence of hygromycin B (data not shown).

Optimization of transformation conditions. We have determined the influence of the following two factors on the transformation efficiency and the rate at which T-DNA is inserted into the host genome: (i) the effect of pretreating the bacterial cells with AS prior to cocultivation, and (ii) the length of the cocultivation period. We grew Agrobacterium tumefaciens cells in IM with and without AS for $6 \mathrm{~h}$ at $28^{\circ} \mathrm{C}$, prior to cocultivation with O-685

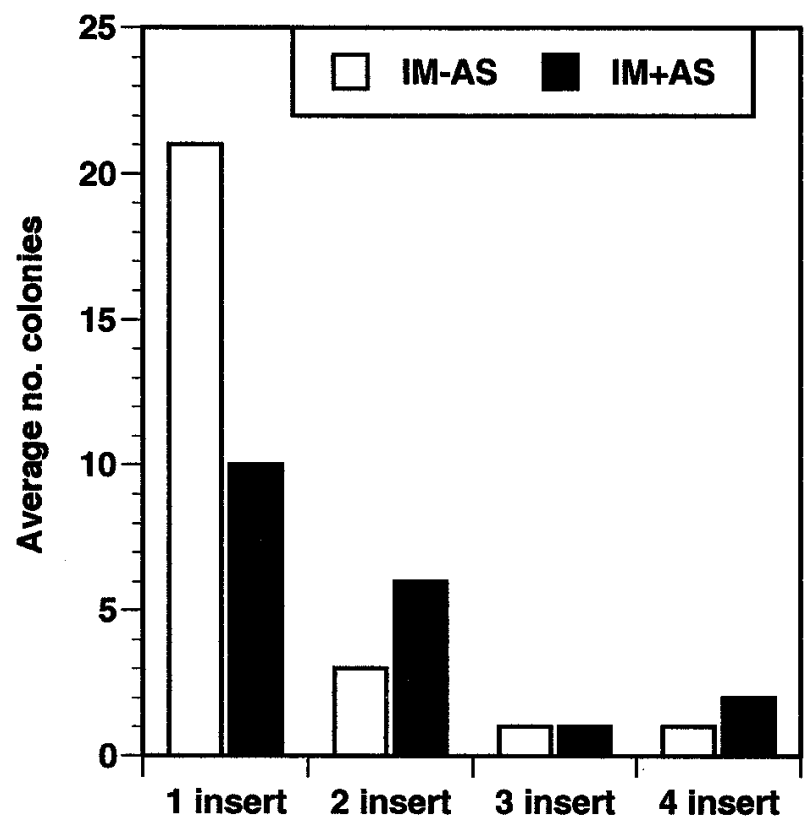

Fig. 4. T-DNA copy number analysis completed in the presence or absence of acetosyringone (AS) on O-685 transformants (19 for induction medium [IM]+AS; 26 for IM-AS). DNA was digested with EcoRI, fragmented on an agarose gel, transferred to a nylon membrane, and probed with a radiolabeled 1.4-kb HpaI fragment of pCB1004. 
conidia. Following every $12 \mathrm{~h}$ of cocultivation, the nitrocellulose filters overlaid with the mix of Agrobacterium tumefaciens cells and fungal conidia were transferred to Aspergillus MM (18) conaining hygromycin B to permit selection. Although the presence of AS during cocultivation was imperative for transformation, the inclusion of AS during the $6 \mathrm{~h}$ growth of Agrobacterium tumefaciens cells prior to cocultivation was not essential (Fig. 3). However, with Agrobacterium tumefaciens cells grown in the absence of AS (IM-AS), the appearance of transformants was substantially delayed relative to that recorded with Agrobacterium tumefaciens cells grown in the presence of AS (IM+AS). Transformation efficiency increased as the cocultivation period increased under both conditions but was consistently lower under the IM+AS condition when the same cocultivation period was used (Fig. 3). The difference in transformation efficiency between the two conditions was less pronounced after $48 \mathrm{~h}$ of cocultivation.

We determined the effect of AS on the percentage of transformants containing a single insert of T-DNA per genome by Southern analysis with the $h p h$ gene as a probe (Fig. 4). The IM-AS condition increased the number of such transformants relative to the IM+AS treatment considerably (Fig. 4). Only 53\% of those transformants generated by Agrobacterium tumefaciens cells grown in the IM+AS condition had a single T-DNA, whereas those derived from Agrobacterium tumefaciens cells grown in the IM-AS condition increased to over $80 \%$. Among those transformants derived from Agrobacterium tumefaciens cells grown in the IM+AS condition, the period of co-incubation did not appear to influence such a frequency. Four of nine transformants $(44 \%)$ derived from the 36-h cocultivation (Fig. 3) possessed a single insert of T-DNA, whereas four of eight transformants $(50 \%)$ derived from the 48-h cocultivation treatment had a single T-DNA insert. We also determined the relationship between the size of transformant colonies and the copy number of T-DNA by grouping transformants into three classes $(<3-\mathrm{mm}$ diameter, 3 - to 6-mm diameter, and $>6$-mm diameter) after 4 days of growth on the selective medium. Similar to cocultivation time, average colony diameter did not correlate with the copy number of T-DNA in either the IM-AS or IM+AS condition (data not shown).

The effect of Agrobacterium tumefaciens cell number on the percentage of transformants containing a single T-DNA insert was also determined. Different volumes of Agrobacterium tumefaciens cells grown in the IM+AS condition (ranging from 5 to $100 \mu \mathrm{l}$ ) were adjusted to $100 \mu \mathrm{l}$ (with IM+AS) and cocultivated with $100 \mu \mathrm{l}$ of conidia $\left(1 \times 10^{6}\right.$ conidia per ml) for $48 \mathrm{~h}$. Not surprisingly, as the Agrobacterium tumefaciens cell number increased, so did the efficiency of transformation $(r=0.996 ; n=3 ; P<0.01$; Table 2). A Southern analysis of six transformants from each condition showed that no significant correlation existed between the average insert number per genome and the quantity of Agrobacterium tumefaciens cells present during the cocultivation period. On average, $56 \%$ of the 30 transformants analyzed possessed a single insert of T-DNA, which was consistent with the result shown in Figure 4.

TABLE 2. Effect of decreasing the volume of Agrobacterium tumefaciens cells available in the cocultivation mix on the efficiency of transformation and the subsequent average copy number of T-DNA ${ }^{\mathrm{a}}$

\begin{tabular}{lcc}
\hline Bacterial cell volume $(\mu \mathrm{l})$ & Transformation efficiency & Copy number \\
\hline 100 & $42 \pm 4.9$ & $1.3 \pm 0.21$ \\
50 & $21 \pm 1.1$ & $1.2 \pm 0.16$ \\
25 & $14 \pm 1.99$ & $1.8 \pm 0.31$ \\
10 & $8.5 \pm 0.49$ & $1.5 \pm 0.22$ \\
5 & $4 \pm 0.99$ & $1.3 \pm 0.21$ \\
\hline
\end{tabular}

${ }^{a}$ Copy number was determined by Southern hybridization using the ${ }^{32} \mathrm{P}$ labeled 1.4-kb HpaI fragment of pCB1004 as a probe. Average number of transformants between three plates \pm standard error. Average copy number of six transformants per treatment \pm standard error.
Cloning and characterization of T-DNA and its flanking sequences. TAIL-PCR was used to isolate the genomic DNA of $F$. oxysporum flanking the site of T-DNA insertion. The potential of TAIL-PCR as a tool for such a purpose has already been established (24). We designed a 16-nucleotide (nt) long AD primer, labeled AD-1, with a calculated melting temperature $\left(T_{m}\right)$ of $47^{\circ} \mathrm{C}$ (Fig. 2). $T_{m}$ 's of primers specific for each border sequence of $\mathrm{T}$ DNA (LB-1, -2 , and -3 for the left border and RB-1, -2 , and -3 for the right border), ranging from 20 to $26 \mathrm{nt}$ in size, were designed to be at least $58^{\circ} \mathrm{C}$ or higher, as previously recommended (25). The $5^{\prime}$ end of LB-3 and RB-3 was 74 and 63 bp apart from the $5^{\prime}$ end of LB-2 and RB-2, respectively, to facilitate the identification of PCR products corresponding to T-DNA insert junctions by size comparison between the secondary and tertiary reaction products.

Employing the AD-1 primer with the RB-specific primers, successful amplification of junction fragments was attained in 7 of the 10 transformants analyzed (Fig. 5). Using AD-1 with the set of LB-specific primers (LB-1, -2, and -3), we successfully amplified junction fragments from eight transformants, two of which corresponded to those that failed to produce a desired product with the $\mathrm{RB}$ primers. The sizes of PCR products ranged from 0.3 to $1.6 \mathrm{~kb}$. As a result of the nested arrangement of the RB and LB primers within one another, the size profile of the desired product was staggered, decreasing with each TAIL-PCR reaction (Fig. 5). The primary reaction typically produced several products. As found previously $(24,25)$, the number of PCR products was reduced with each successive reaction. In some transformants, more than one junction product was amplified presumably due to the presence of multiple annealing sites of AD-1 in the vicinity of the inserted TDNA (Fig. 5).

A sequence comparison of 15 junction fragments (7 RB and $8 \mathrm{LB}$ ) suggested that the insertion of T-DNA within the host genome appears to be a random event (Fig. 6). The F. oxysporum sequences flanking the insertion sites revealed no significant similarity among each other or with the T-DNA border sequences. Truncation of the inserted T-DNA, ranging from 1 to $25 \mathrm{bp}$ in size, occurred on both the right and left border sequences, but more frequently with the latter (RB 28\% versus LB 38\%). Using the BLASTX algorithm (NCBI, Bethesda, MD) no significant similarity was found between the genomic DNA sequences flanking inserted T-DNA and those present in the GenBank database.

Construction of additional Agrobacterium tumefaciens binary vectors for fungal transformation. Additional Agrobacte-

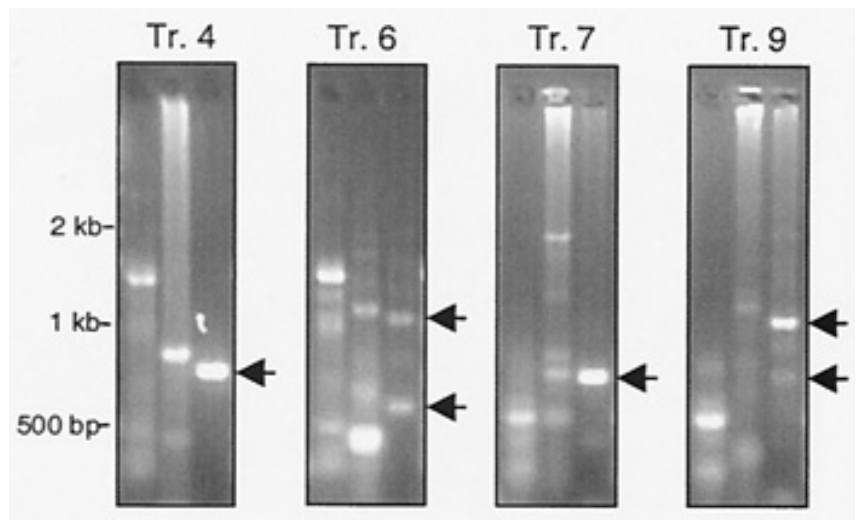

Fig. 5. Agarose gel analysis of thermal asymmetric interlaced polymerase chain reaction (TAIL-PCR) products generated from four representative transformants. Amplification of transformants Tr. 4 and Tr. 6 was performed with the right border (RB) nest of primers (RB-1, -2, and -3) with arbitrary degenerate primer (AD)-1. Tr. 7 and Tr. 9 were amplified with AD-1 and the left border (LB) set of specific primers (LB-1, -2, and -3). The first, second, and third lanes of each gel (from left to right) represent the primary, secondary, and tertiary reactions, respectively, of the protocol. Arrows label TAIL-PCR products corresponding to junction fragments containing segment of inserted T-DNA and associated flanking fungal DNA. 
rium tumefaciens binary vectors were constructed to facilitate ATMT and the subsequent analysis of generated transformants. To permit plasmid rescue as an alternative means of isolating the genomic DNA flanking the site of T-DNA insertion, we constructed pKHt (Fig. 1). This vector contains the ColE1 replication of origin and the gene conferring chloramphenicol resistance in the multiple cloning site of pBHt2. Subsequently, inserted T-DNA along with its flanking genomic DNA can be cloned into Escherichia coli as a replicating plasmid. pBHt2, created as an intermediate vector in the construction of $\mathrm{pKHt}$, is identical to pBHt1 except that it lacks several restriction sites (ClaI, EcoRI, PstI, and SacII) present in the Aspergillus nidulans trpC promoterhph fragment of pBHt1. Transformation efficiencies with Agrobacterium tumefaciens cells carrying either $\mathrm{pBHt} 2$ or $\mathrm{pKHt}$ were comparable with those recorded with $\mathrm{pBHt} 1$. Under the IM+AS condition, $50 \%$ of the transformants by pKHt (16 transformants analyzed) contained a single insert of T-DNA (data not shown), which was consistent with the result obtained with pBHt1 (Fig. 4). As a tool for gene replacement mediated by ATMT, we constructed pDHt. In lacking the CaMV35S promoter and $h p h$ gene, originally present in pCAMBIA1300, pDHt is 7.1-kb long and has 10 unique restriction sites for cloning a target fungal gene disrupted by a gene conferring antibiotic resistance $(h p h)$.

\section{DISCUSSION}

In this report we describe (i) the construction of novel binary vectors for insertional mutagenesis and gene transfer in fungi, (ii) the conditions of ATMT that affect the transformation efficiency and the copy number of inserted T-DNA in $F$. oxysporum, a fungal pathogen of agricultural significance, and (iii) an efficient TAILPCR approach for cloning fungal genes tagged by T-DNA. In prior studies, the transformation of $F$. oxysporum was achieved with vectors containing either homologous (the nitrate reductase gene) or heterologous (either the hph gene or the Aspergillus nitrate reductase gene) selection markers $(14,19,22,28,36)$. These studies, however, have had to rely on the isolation of fungal protoplasts. In contrast, Agrobacterium tumefaciens can transform protoplasts, hyphae, spores (8), and blocks of mushroom mycelial tissue (P. Romaine, unpublished data). In this work we transformed conidia and avoided the problems (low yield and viability) typically associated with the time consuming process of protoplast isolation.

Whereas the transformation of a Fusarium sp. (F. venenatum) by ATMT has been reported (8), the level of efficiency (2.5 per $1 \times 10^{6}$ conidia) was two orders of magnitude lower than that of $F$. oxysporum (300 to 500 transformants per $1 \times 10^{6}$ conidia). Because our ATMT procedure is comparable with that published before (8), it is possible that this difference could be explained by certain biological differences between the fungal species tested. However, we cannot rule out the probability that the difference in the promoter driving the expression of the hph gene (Aspergillus nidulans $\operatorname{trp} C$ in this study versus Aspergillus nidulans gpd in the previous study) underlies this significant difference in transformation efficiency. Considering the significant correlation $(r=0.996$; $n=3 ; P<0.01)$ that was attained between the Agrobacterium tumefaciens cell number and the efficiency of transformation (Table 2), the transformation efficiency of $F$. oxysporum by ATMT can potentially be further improved by increasing the Agrobacterium tumefaciens cell number. Pretreating the Agrobacterium tumefaciens cells in the presence of AS will also increase the number of transformants generated (Fig. 3). Although the cocultivation period correlated positively with the efficiency of transformation, a longer cocultivation period is not recommended for $F$. $o x$ ysporum (Fig. 3). Even after the 2 days of cocultivation, Fusarium conidia germinated and grew substantially. Excessive mycelial growth prior to hygromycin B selection would therefore complicate the subsequent isolation of individual transformants. However, an increased cocultivation period is an option for maximizing the transformation efficiency of those fungi that grow slower than $F$. oxysporum.

Another potential advantage of ATMT over conventional transformation techniques is that it appears to significantly increase the frequency of gene replacement when a mutated gene from the transformation host was cloned between the T-DNA border sequences. In Kluyveromyces lactis the frequency of gene replacement by ATMT was more than 10 times higher than that by electroporation with linear double-stranded DNA (5). If this property proves to be true in other fungi, ATMT will offer a highly efficient means for targeted gene knockout. To take advantage of this, we constructed a novel binary vector $\mathrm{pDHt}$ that only contains the multiple cloning sites (10 unique restriction sites) between the TDNA border sequences.

Although the colony size of transformants generated with pCAMBIA1300 were smaller than those created by pBHt1, the transformation efficiency of $F$. oxysporum achieved with pCAMBIA1300 was comparable to that with $\mathrm{pBHt}$, indicating that the CaMV35S promoter functions in this fungus and probably in other ascomycetes. The significance of this finding is that a large array of Agrobacterium tumefaciens binary vectors, currently available for plant transformation, can be utilized to transform fungi without further modification. The CaMV35S promoter is by far the most popular promoter for driving a selectable marker gene in plant transformation, and binary vectors carrying the hygromycin B or bialaphos resistance gene under the control of the CaMV35S promoter are therefore likely to be available in most plant molecular biology laboratories. Whereas a transcription terminator derived from CaMV was used for the $h p h$ gene in both pCAMBIA1300 and pBHt1, a transcription terminator is not essential for the expression of the $h p h$ gene (6). It is therefore unlikely that the continued presence of the CaMV poly (A) signal at the $3^{\prime}$ end of the $h p h$ gene would have any negative affect on $h p h$ expression.

For fungi lacking a sexual cycle, such as $F$. oxysporum, an important preliminary step for using ATMT as a tool for insertional mutagenesis is to find conditions that minimize the rate of T-DNA insertion to at most one event per transformant. Although the

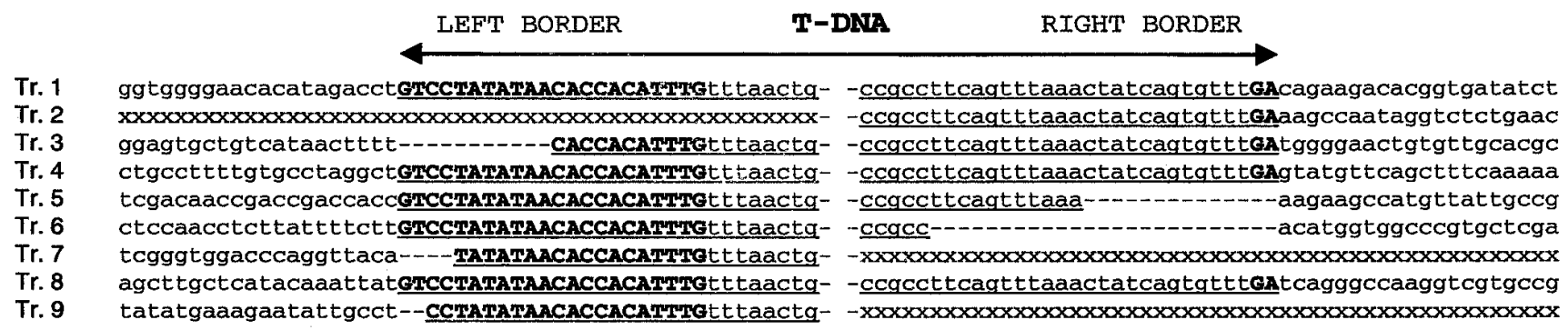

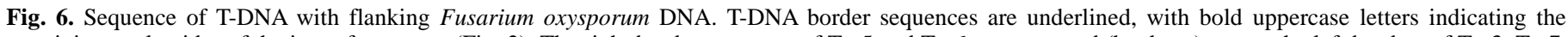

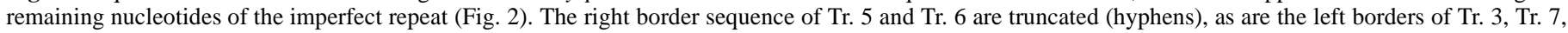
and Tr. 9. Sequence data for Tr. 2 (left border) and Tr. 7 and Tr. 9 (right border) was not obtained, and is indicated by x. 
transformation efficiency was significantly enhanced by prolonging the bacterial-fungal cell cocultivation time and by increasing the number of Agrobacterium tumefaciens cells, the percentage of transformants carrying a single T-DNA insert per fungal genome was independent of these variables (Fig. 4 and Table 2). Furthermore, the colony size of hygromycin B resistant transformants was not a reliable indicator for the rate of T-DNA insertion, which rejects the hypothesis that the larger the size of the transformant, the more copies of T-DNA has been inserted therein. The presence of AS is essential for successful ATMT $(4,8)$ and as shown here, when included in the culturing media of the Agrobacterium tumefaciens cells, was the only factor that influenced the rate of TDNA insertion into the host genome (Fig. 4). In its absence from the 6-h bacterial cell pretreatment, over $80 \%$ of the tested transformants had experienced single insertions, whereas its inclusion resulted in almost $50 \%$ of the generated transformants possessing multiple T-DNA inserts.

Having designed novel primer sets and demonstrated their effectiveness, we have established TAIL-PCR as a rapid, effective strategy for isolating the host DNA sequence flanking a site of TDNA insertion in $F$. oxysporum. Using only one arbitrary primer (AD-1) in combination with either the LB or the RB primers, we were able to isolate PCR fragments spanning one or both of the insertion junctions of T-DNA from $90 \%$ of the transformants tested. It is likely that $100 \%$ efficiency could be attained with the use of additional AD primers. One concern with TAIL-PCR is that if the border sequences become truncated beyond the annealing site for the amplifying borders, amplification of the desired product would not be possible. In spite of the fact that such an event appears unlikely in $F$. oxysporum (Fig. 5), where the extent of truncation ( 2 to $25 \mathrm{bp}$ ) was substantially lower than that (1 to $82 \mathrm{bp}$ ) seen in Aspergillus awamori (8), we constructed the pKHt vector. Containing the ColE1 origin of replication and the chloramphenicol resistance gene within the multiple cloning sites, this vector will permit both TAIL-PCR and plasmid rescue for cloning fungal genes tagged by T-DNA.

The use of Agrobacterium tumefaciens as an insertional mutagen in Arabidopsis has resulted in the establishment of large T-DNA transformed populations that are now accessible to the scientific community (21). One of the objectives of this study was to test the feasibility of ATMT as a tool for the insertional mutagenesis of $F$. oxysporum. The systematic analysis of fungal genes important for pathogenicity has been greatly assisted by REMI $(1-3,16,23,30,34,37)$ whereby the mutated gene, as a result of being tagged by the foreign DNA, can be cloned easily. We believe that ATMT could offer an alternative approach for the efficient insertional mutagenesis of fungi (10), which may circumvent some of the shortcomings of REMI. A previous study showed that $<20 \%$ Arabidopsis mutants generated by ATMT were untagged by T-DNA (12). However, another study reported a much higher frequency (64\%) of untagged mutants in Arabidopsis (7). It remains to be determined whether ATMT also generates a significant percentage of untagged mutants in fungi as has also been observed in some fungal mutants generated by REMI $(2,11$, $23,31,34)$. If the frequency of untagged mutants by ATMT is low in fungi, it will be especially suitable for creating a mutant library of $F$. oxysporum as well as other fungi that lack the sexual stage.

Although we have used $F$. oxysporum as the sole host for ATMT, the binary vectors and protocols developed in this study are applicable to transform other fungi. In a preliminary experiment with pBHt1 (S. Kang, unpublished data), the transformation efficiency of three different strains of Verticillium dahliae ranged from less than 50 per $1 \times 10^{6}$ conidia (with an isolate from bell pepper) to 500 per $1 \times 10^{6}$ conidia (with an isolate from cabbage). The efficiency with $M$. grisea, using $\mathrm{pBHt} 2$, was approximately 200 per $1 \times 10^{6}$ conidia after $36 \mathrm{~h}$ of cocultivation (Y.-H. Lee at Seoul National University, personal communication), which was similar to what we observed with $F$. oxysporum. However, both
pBHt1 and pCAMBIA1300 failed to transform Agaricus bisporus (button mushroom), suggesting that neither the Aspergillus. nidulans $\operatorname{trp} C$ promoter nor the CaMV35S promoter function properly in Agaricus bisporus.

We have demonstrated in this paper that the vectors we have constructed and the protocol modifications we have made significantly enhance the effectiveness of ATMT to the point that its use can now be broadly adopted to study gene function in a large group of fungal pathogens. Furthermore, our vectors are significantly smaller in size (pBHt1, 8.4 kb and pBHt2, $8.4 \mathrm{~kb})$ than the plasmid (pUR5750, $14 \mathrm{~kb}$ ) previously used (8). Although the size of a binary vector is unlikely to become a critical factor with respect to transformation efficiency, the disparity between the vectors will be crucial when additional genes need to be cloned into the vectors to carry out gene transfer. The utility of pBHt 2 as a vehicle for gene delivery is further enhanced by the fact that it contains nine unique restriction sites, in contrast to the four located on pUR5750.

In spite of the earlier publications describing the potential of this procedure, ATMT has not featured prominently in literature. We believe that because of the successful transformation of a large number of fungi by Agrobacterium tumefaciens and the other advantages it possesses over protoplast-based transformation techniques (8), coupled with the availability of our vectors to the community, the full potential of ATMT as a means for facilitating the genetic manipulation of diverse plant pathogenic fungi will be realized.

\section{ACKNOWLEDGMENTS}

This research was supported by The Pennsylvania State University Innovative Biotechnology Research Fund (IBRF). We thank M. Guiltinan (Dept. Biology, The Pennsylvania State University) for providing the Agrobacterium tumefaciens strain and B. C. Wu for technical assistance.

\section{LITERATURE CITED}

1. Akamatsu, H., Itoh, Y., Kodama, M., Otani, H., and Kohmoto, K. 1997. AAL-toxin deficient mutants of Alternaria alternata tomato pathotype by restriction enzyme-mediated integration. Phytopathology 87:967-972.

2. Balhadère, P. V., Foster, A. J., and Talbot, N. J. 1999. Identification of pathogenicity mutants of the rice blast fungus Magnaporthe grisea by insertional mutagenesis. Mol. Plant-Microbe Interact. 12:129-142.

3. Bölker, M., Böhnert, H. U., Braun, K. H., Görl, J., and Kahmann, R. 1995. Tagging pathogenicity genes in Ustilago maydis by restriction enzyme-mediated integration (REMI). Mol. Gen. Genet. 248:547-552.

4. Bundock, P., den Dulk-Ras, A., Beijersbergen, A., and Hooykaas, P. J. J. 1995. Trans-kingdom T-DNA transfer from Agrobacterium tumefaciens to Saccharomyces cerevisiae. Eur. Mol. Biol. Organ. 14:3206-3214.

5. Bundock, P., Mroczek, K., Winkler, A. A., Steensma, H. Y., and Hooykas, P. J. J. 1999. T-DNA from Agrobacterium tumefaciens as an efficient tool for gene targeting in Kluyveromyces lactis. Mol. Gen. Genet. 261:115-121.

6. Carroll, A. M., Sweigard, J. A., and Valent, B. 1994. Improved vectors for selecting resistance to hygromycin. Fungal Genet. Newsl. 41:22.

7. Castle, L. A., Errampalli, D., Atherton, T. L., Franzmann, L. H., Yoon, E. S., and Meinke, D. W. 1993. Genetic and molecular characterization of embryonic mutants identified following seed transformation in Arabidopsis. Mol. Gen. Genet. 241:504-514.

8. de Groot, M. J. A., Bundock, P., Hooykaas, P. J. J., and Beijersbergen, A. G. M. 1998. Agrobacterium tumefaciens-mediated transformation of filamentous fungi. Nature Biotech. 16:839-842.

9. Dikes, B. P., and Feldmann, K. A. 1998. Cloning genes from T-DNA tagged mutants. Pages 339-351 in: Arabidopsis Protocols, vol. 82. Humana Press, Totowa.

10. Dunn-Coleman, N., and Wang, H. 1998. Agrobacterium T-DNA: A silver bullet for filamentous fungi? Nature Biotech. 16:817-818.

11. Epstein, L., Lusnak, K., and Kaur, S. 1998. Transformation-mediated developmental mutants of Glomerella graminicola (Collectotrichum graminicola). Fungal Genet. Biol. 23:189-203.

12. Feldmann, K. A. 1991. T-DNA insertion mutagenesis in Arabidopsis: Mutational spectrum. Plant J. 1:71-82.

13. Fisher, N. L., Burgess, L. W., Toussoun, T. A., and Nelson, P. E. 1982. Carnation leaves as a substrate and for preserving cultures of Fusarium 
species. Phytopathology 72:151-153.

14. Garcia-Pedrajas, M. D., and Roncero, M. I. G. 1996. A homologous and self-replicating system for efficient transformation of Fusarium oxysporum. Curr. Genet. 29:191-198.

15. Gouka, R. J., Gerk, C., Hooykaas, P. J. J., Bundock, P., Musters, W., Verrips, C. T., and de Groot, M. J. A. 1999. Transformation of Aspergillus awamori by Agrobacterium tumefaciens-mediated homologous recombination. Nature Biotech. 17:598-601.

16. Granado, J. D., Kertesz-Chaloupkova, K., Aebi, M., and Kues, U. 1997. Restriction enzyme-mediated DNA integration in Coprinus cinereus. Mol. Gen. Genet. 256:28-36.

17. Hooykaas, P. J. J., Roobol, C., and Schilperoort, R. A. 1979. Regulation of the transfer of Ti-plasmids of Agrobacterium tumefaciens. J. Gen. Microbiol. 110:99-109.

18. Käfer, E. 1977. Meiotic and mitotic recombination in Aspergillus and its chromosomal aberrations. Adv. Genet. 19:33-131.

19. Kistler, H. C., and Benny, U. K. 1988. Genetic transformation of the fungal plant wilt pathogen Fusarium oxysporum. Curr. Genet. 13: 145-149.

20. Koncz, C., Németh, K., Rédei, G. P., and Schell, J. 1992. T-DNA insertional mutagenesis in Arabidopsis. Plant Mol. Biol. 20:963-976.

21. Krysan, P. J., Young, J. C., and Sussman, M. R. 1999. T-DNA as an insertional mutagen in Arabidopsis. Plant Cell 11:2283-2290.

22. Langin, T., Daboussi, M. J., Gerlinger, C., and Brygoo, Y. 1990. Influence of biological parameters and gene transfer technique on transformation of Fusarium oxysporum. Curr. Genet. 17:313-319.

23. Linnemannstöns, P., Vob, T., Hedden, P., Gaskin, P., and Tudzynski, B. 1999. Deletions in the gibberellin biosynthesis gene cluster of Gibberella fujikuroi by restriction enzyme-mediated integration and conventional transformation-mediated mutagenesis. Appl. Envir. Microbiol. 65:2558-2564.

24. Liu, Y.-G., Mitsukawa, N., Oosumi, T., and Whittier, R. F. 1995. Efficient isolation and mapping of Arabidopsis thaliana T-DNA insert junctions by thermal asymmetric interlaced PCR. Plant J. 8:457-463.

25. Liu, Y.-G., and Whittier, R. F. 1995. Thermal asymmetric interlaced PCR: Automatable amplification and sequencing of insert end fragments from P1 and YAC clones for chromosome walking. Genomics 25:674-681.

26. Lu, S., Lyngholm, L., Yang, G., Bronson, C., and Yoder, O. C. 1994.
Tagged mutations at the Tox1 locus of Cochliobolus heterostrophus by restriction enzyme-mediated integration. Proc. Natl. Acad. Sci. USA 91:12649-12653.

27. Mazars, G.-R., Moyret, C., Jeanteur, P., and Theillet, C.-G. 1991. Direct sequencing by thermal asymmetric PCR. Nucleic Acids Res. 19:4783.

28. Migheli, Q., Friard, O., Del Tedesco, D., Musso, M. R., and Gullino, M. L. 1996. Stability of transformed antagonistic Fusarium oxysporum strains in vitro and in soil microcosms. Mol. Ecology 5:641-649.

29. O’Donnell, K., and Cigelnik, E. 1997. Phylogenetic relationships among ascomycetous truffles and the true and false morels from $18 \mathrm{~S}$ and $28 \mathrm{~S}$ ribosomal DNA sequence analysis. Mycologia 89:48-65.

30. Redman, R. S., Ranson, J. C., and Rodriguez, R. J. 1999. Conversion of the pathogenic fungus Colletotrichum magna to a nonpathogenic endophytic mutualist by gene disruption. Mol. Plant-Microbe Interact. 12:969-975.

31. Sanchez, O., Navarro, R. E., and Aguirre, J. 1998. Increased transformation frequency and tagging of developmental genes in Aspergillus nidulans by restriction enzyme-mediated integration (REMI). Mol. Gen. Genet. 258:89-94.

32. Shi, Z., and Leung, H. 1995. Genetic analysis of sporulation in Magnaporthe grisea by chemical and insertional mutagenesis. Mol. PlantMicrobe Interact. 8:949-959.

33. Staben, C., Jensen, B., Singer, M., Pollock, J., Schechtman, M., Kinsey, J., and Selker, E. 1989. Use of a bacterial hygromycin B resistance gene as a dominant selectable marker in Neurospora crassa transformation. Fungal Genet. Newsl. 36:79-81.

34. Sweigard, J. A., Carroll, A. M., Farrall, L., Chumley, F. G., and Valent, B. 1998. Magnaporthe grisea pathogenicity genes obtained through insertional mutagenesis. Mol. Plant-Microbe Interact. 11:404-412.

35. Sweigard, J. A., Orbach, M. J., Valent, B., and Chumley, F. G. 1990. A miniprep procedure for isolating genomic DNA from Magnaporthe grisea. Fungal Genet. Newsl. 37:44.

36. Toyota, K., Tsuge, T., and Kimura, M. 1992. Potential application of genetic transformants of Fusarium oxysporum f. sp. raphani for assessing fungal autecology. Soil Biol. Biochem. 24:489-494.

37. Yun, S.-H., Turgeon, B. G., and Yoder, O. C. 1998. REMI-induced mutants of Mycosphaerella zeae-maydis lacking the PM-toxin are deficient in pathogenesis to corn. Physiol. Mol. Plant Pathol. 52:53-66. 